\title{
RESEARCH
}

\section{An Update on the Kiersma Chen Empathy Scale (KCES): Creating the KCES-Revised}

\author{
Benjamin D. Aronson, PharmD, PhD, ${ }^{\mathrm{a}}$ Aleda M. H. Chen, PharmD, PhD, ${ }^{\mathrm{b}}$ Michelle L. Blakely, PhD, MEd, ${ }^{\mathrm{c}, \mathrm{d}}$ \\ Mary E. Kiersma, PharmD, PhD, ${ }^{\mathrm{e}}$ Emily Wicker, PharmD ${ }^{\mathrm{b}}$ \\ ${ }^{\text {a }}$ Ohio Northern University, Raabe College of Pharmacy, Ada, Ohio \\ ${ }^{\mathrm{b}}$ Cedarville University, School of Pharmacy, Cedarville, Ohio \\ ${ }^{\mathrm{c}}$ University of Wyoming, School of Pharmacy, Laramie, Wyoming \\ ${ }^{\mathrm{d}}$ Editorial Board Member, American Journal of Pharmaceutical Education, Arlington, Virginia \\ ${ }^{\mathrm{e}}$ Accreditation Council for Pharmacy Education (ACPE), Chicago, Illinois
}

Corresponding Author: Aleda M. H. Chen, Cedarville University, School of Pharmacy, 251 N. Main St., Cedarville, OH 45314. Tel: 937-766-7454. Email: amchen@ cedarville.edu

Submitted April 10, 2021; accepted August 16, 2021; ePublished September 2021

Objective. This study aimed to provide further validity evidence for the KCES by analyzing data collected from multiple administrations of the KCES along with cognitive interviews of students in pharmacy and nursing programs to identify revisions of the Kiersma-Chen Empathy Scale: The KCES- Revised (KCES-R).

Methods. De-identified data from previous KCES administrations were used for scale evaluation. Response process validity evidence was enhanced through cognitive interviews with 20 pre-pharmacy/pharmacy students at Cedarville University. After survey revisions, the cognitive interview process was repeated with 10 University of Wyoming nursing students.

Results. Based on psychometric data and cognitive interviews, the KCES was revised as follows: (1) key components of cognitive and affective empathy were retained, (2) scaling was changed to reflect necessity and empathy ability, (3) negatively-worded items were removed, and (4) instrument was changed to two parallel subscales.

Conclusion. This study used data from thousands of geographically and professionally diverse samples. Based on potential problems identified in quantitative analyses, cognitive interviews with nursing and pharmacy students were conducted, and modifications to the KCES were made. Further psychometric validation is needed regarding the KCES-R. Keywords: Kiersma Chen Empathy Scale (KCES), empathy, pharmacy, cognitive interviews, validity evidence

\section{INTRODUCTION}

Empathy is the subjective identification of another individual's cognitive and emotional state. ${ }^{1,2}$ Health care providers are expected to empathize with their patients throughout the patient/provider relationship. Empathy can greatly impact patient adherence, satisfaction, and treatment outcomes. ${ }^{1}$ For example, Dambha-Miller and colleagues (2019) found that patients with type II diabetes in a cohort study who experienced greater empathy from their provider had a lower all-cause mortality. ${ }^{3}$

Due to the positive impact on patient care, empathy is an important skill in health professional education. Pharmacy, nursing, and medical educational standards also include empathy within the standards or as part of patientcentered communication. ${ }^{4-7}$ However, due to the subjective nature of empathy and communication skills, teaching and assessing empathy is difficult. Current interventions include watching patient interviews, serving the underserved, simulated and actual patient encounters, and role-playing as patients. ${ }^{1}$ To ensure that interventions are effective in teaching empathy, they must be assessed. However, there are limited assessments which have been validated for use in assessing student empathy. In order to assess health professional students' empathy, the Kiersma-Chen Empathy Scale (KCES) was developed and validated. ${ }^{8}$

To ensure external validity, assessment tools must be continually evaluated for consistency and effectiveness. Psychometric testing can be performed on large, diverse datasets in order to evaluate item reliability and validity. ${ }^{9}$ The KCES has been used in over 80 studies internationally to assess empathy expressed by health professional students due to its development in pharmacy and nursing students as well as the free use of the scale with permission. These studies have provided evidence of the relationships between KCES scores and positive impacts of educational interventions to improve empathy, conflict management, and willingness to provide care. ${ }^{10-14}$ Yet, despite its widespread use and some validity evidence, the major source of validity evidence for the KCES is its original validation. ${ }^{8}$ There exists an opportunity to investigate the psychometric properties of KCES using data from its many administrations, which could identify potential 
measurement issues or possible changes to improve the scale clarity or validity. Additionally, cognitive interviewing can be used to identify survey items that have misalignment between participant interpretation and the developer's intentions. ${ }^{15}$ Cognitive interviews help identify ways to modify any misaligned items based on participant response. ${ }^{15}$

This study aimed to provide further validity evidence for the KCES by examining data collected from end-users (educators and researchers) who have administered the KCES. These analyses along with cognitive interviews of students in pharmacy and nursing programs were used to identify changes that could be made to the KCES. Ultimately, the goal was to create a revised version of the scale - KCES-R.

\section{METHODS}

The KCES, described elsewhere, ${ }^{8}$ was created from the idea that empathy includes both cognitive and affective elements - both understanding and connecting to perspectives and experiences. The researchers generated a list of items, ultimately utilizing 15 items (nine - cognitive, six - affective). Students indicated their level of agreement with the statements using a 7-point, Likert-type scale. Additionally, four items were reverse-coded; scores could range from 15 to 105, with higher scores indicating greater empathy. After administering to 216 pharmacy and nursing students, the KCES was positively correlated to a commonly-used measure of empathy (the Jefferson Scale of Empathy - Health Professional Students, $p<.01$ ), had a high Cronbach's alpha (.85), and good reliability (.86). However, the confirmatory factor analysis (CFA) model did not indicate acceptable fit due to the covariance of the affective and cognitive domains. ${ }^{8}$

Cedarville University's (CUSOP) Institutional Review Board approval was obtained to analyze all KCES data shared as of May 2020. De-identified data from KCES administrations were shared for scale development purposes. Users most often provided raw single item responses from the KCES at baseline, and some post-intervention and end-of-course administrations. When raw responses were not shared, those data were requested. Some administrations included the sum score of the KCES calculated by the user, and sample demographics (ie, age, gender, program of study, type of employment, year in school).

These data informed the development of questions for the cognitive interviews. In addition to the analysis of the raw data, informal feedback from researchers who utilized the KCES along with preliminary psychometric analyses indicated potential issues with items that were negatively-worded. Whether the cognitive and affective domains could be separable also was an area of discussion by the research team. Thus, validity evidence of the response process was enhanced by performing cognitive interviews first with 20 CUSOP pre-pharmacy/pharmacy students. Students were provided with a paper KCES and asked to read each question aloud. Probing questions were used to ascertain students' understanding of items, retrieval of information for items, judgement related to items, response to items, and adequacy of items. ${ }^{15}$ Potential rewording options of the KCES were proposed to participants to determine which scaling approach best captured their empathy perceptions due to a potential ceiling effect and avoiding bias related to agree/disagree. Rewording options included: false vs true, yes vs no, and level of description of the individual or feelings. The students had a copy of the original KCES, and the rewording of the items, including the scaling approach, were presented verbally for comparison. After the survey was revised, a second cognitive interview process was performed with 10 nursing students from the University of Wyoming using probing questions.

\section{Data Analysis}

The research team analyzed quantitative data using SPSS (v.25) for summary, scale, bivariate statistics, and exploratory factor analysis (EFA), and MPlus (Version 1.4) for CFA. Individual item responses were explored, including response patterns, mean, standard deviation, range, skewness, and kurtosis. Bivariate correlations between items at baseline were computed, as well as item-scale statistics for the subscales to determine homogeneity of the construct. Cronbach's alpha, for the subscales and overall scale, was also computed as a measure of internal consistency.

Paired t-tests were conducted to explore responsiveness to change and test-retest reliability for multiple administrations to the same individuals. Additionally, sum scores computed using the raw data were compared to usercalculated sum scores to explore if scale scoring procedures were used correctly (eg, reverse coding four of the items).

The original validation of the KCES suggested two factors, consistent with the theoretical framework used to develop the scale, whereby items $1,3,4,6,8,10,13,14$, and 15 loaded on one factor (ie, cognitive domain) and items 2 , $5,7,9,11$, and 12 loaded on another factor (ie, the affective domain). ${ }^{8}$ In the present study, the data were fit to a twofactor confirmatory model in MPlus to provide validity evidence of internal structure. An alternative 1-factor model, with all items loading on one factor, was also fit. Model fit was deemed to be appropriate using the joint criteria of a comparative fit index (CFI) greater than or equal to .95 , root mean square error of approximation (RMSEA) $\leq .06$, and standardized root mean square residual $(\mathrm{SRMR}) \leq .08 .{ }^{16}$

An EFA was conducted using Principal Axis Factoring and Varimax rotation. Items with low inter-item correlations (ie, $r<.3$ ) were removed prior to further analyses. The number of factors to retain was based on convergence 
of the following considerations: eigenvalues $\geq 1$, inspection of the scree plot, and a parallel analysis (ie, Eigenvalue Monte Carlo Simulation) with 1000 parallel data sets using permutations of the raw data set and the $95 \%$ confidence interval. ${ }^{17}$ Kaiser-Meyer-Olkin (KMO) measure and Bartlett's Test of Sphericity were inspected prior to interpreting results.

Cognitive interviews were audio-recorded and field notes taken (pharmacy: AC, MK, BA; nursing: MB). Items that were judged confusing or interpreted multiple ways, and ways inconsistent with scale authors' intent, were either removed or reworded to improve clarity and consistency of interpretation. Three authors (AC, MK, BA) worked iteratively on rewording and revising the scale until agreement was obtained. Then, the revised scale underwent a second round of cognitive interviewing in a different health profession (nursing) for further pretesting.

\section{RESULTS}

From March 2011 to May 2020, data from a total of 47 separate administrations (7,712 responses, 3 countries) were collected. Respondents included student pharmacists, student nurses, physical therapy students, nurses, and physicians. After removing those with non-meaningful responses (ie, answering all items using identical response categories despite reverse-worded items), there were 7,660 usable baseline KCES responses, with 7,499 answering $\geq 9$ items, and 6,629 answering all 15 items. There were also 3,988 usable post-intervention responses to the KCES shared, and 211 end-of-course responses. User-calculated sum scores were present for 1,993 baseline, 521 post-intervention, and 87 end-of-course responses.

Item and scale descriptive statistics are displayed in Table 1, providing a wealth of data on the performance of the items within the KCES under real-world conditions. All responses contained an answer for the first item of the KCES $(\mathrm{n}=7660)$; item 5 was the most missed/skipped item (9.4\% missed/skipped), followed by item 13 (5.1\% missed/skipped), and item 6 (5\% missed/skipped). Item means were well above the midpoint of the response categories (4) for most items. Notably, the reverse coded items (items $4,9,11,15$ ) had lower averages and were more dispersed than the non-reversed items. Left skew and positive (or peaked) kurtosis were observed for several of the items. Inter-item correlations between items within each domain (ie, cognitive and affective) were mixed, in all cases ranging from non-statistically significant or negligible correlations, to moderate/strongly correlated. In particular, the reverse coded items were problematic here, items 9 and 11 correlated with one another $(r=.62, p<.01)$, and items 4 and 15 with one another $(r=.58, p<.01)$, but lacked any moderate or strong correlations with other items. Corrected item-scale correlations were low $(r<.3)$ for items $2,3,4$, and 15 when grouped by domain, indicating poor fit with other items and possible heterogeneity. ${ }^{18,19}$ Additionally, corrected item-scale correlations were computed for the entire 15 items (not shown); this analysis indicated the reverse coded items 4, 9, 11, and 15 as having potentially poor fit with the other items in the scale $(r<.3)$. Cronbach's alpha for the cognitive domain, affective domain, and sum KCES were $.67, .58$, and .72 respectively.

Because the KCES is commonly used to measure growth in empathy after some form of curricular intervention, responsiveness to change and test-retest reliability were computed using paired t-tests and correlations for pre-post responses. Some of these responses also contained an end of course administration of the KCES, further temporally removed from the first administration. For the full scale, the pre-scores were correlated with post-scores $(r=.67, p<.01)$, with post-intervention scores significantly higher than pre-intervention scores (86.6 vs. 84.0, $p<.01)$ among 3,925 responses with both pre/post-data. Additionally, 194 responses were collected pre-intervention, post-intervention, and course end. Among these individuals, KCES pre-scores were positively correlated with post-scores $(r=.764, p<.01)$ and course-end scores $(r=.66, p<.01)$, and post-scores were positively correlated with end of course-scores $(r=.70, p<.01)$. Differences between pre/post-scores (79.6 vs. 81.7, $p=.01)$ and pre/course-end scores (79.6 vs. 82.5, $p<.01)$ were found, while no significant differences were found between post- and end of course-scores (81.7 vs. 82.5, $p=.24)$. Results for the individual domains were similar with only a few differences for those with pre-, post-, and end of course-scores.

Differences between course-end and post-intervention on the cognitive domain were significant (47.9 vs. 49.0, $p=.02)$, while no significant differences were found between affective domain scores from pre/post $(p=.20)$, pre/course-end $(p=.71)$, and post/course-end ( $p=.30)$.

The KCES contains a series of instructions for analyzing the data to reverse code 4 oppositely worded items; if this analysis stage is overlooked, it would result in KCES sum scores that misrepresent the 'true' empathy of a respondent. For 1,793 responses, user-calculated sum scores for the KCES were included in the dataset. These scores were compared to the sum KCES scores calculated in the present study using participant responses (hereafter referred to as "true score"). A total of only $13.9 \%$ of user-calculated scores matched the true score, with user-calculated scores ranging from \pm 24 the true score. Most (57.2\%) user-calculated scores were within \pm 6 of the true score. User-calculated scores and true scores were significantly different $(p<.01)$. Similar differences in score calculation were seen for post-intervention and end-ofcourse scores.

Validity evidence of dimensionality was originally established through EFA. ${ }^{8}$ Here, CFA of the large pool of responses was used to test the original 2-factor model (ie, cognitive domain and affective domain), as well as a 
unidimensional model where all 15 items loaded on 1 factor. The total $\mathrm{n}$ for these analyses was 7,660, with missing data being estimated using maximum likelihood. Model fit for both models was poor (Table 2), indicating that the KCES may have an alternate factor structure instead of one global empathy domain, or separate cognitive and affective domains.

Hence, EFA was used to investigate alternative factor structure. Items 4, 9, 11, and 15 were eliminated from this analysis due to low inter-item correlations $(r<.3)$. The resultant matrix had a determinant value of .017, and a significant result from Bartlett's Test of Sphericity (chi-square 26987.481, df 55, $p<.01$ ), which show the data to be factorable. The KMO value was 0.88 , which indicates a sufficient sampling adequacy. No items had low loadings on all factors $(<.3)$, or strong loadings on multiple factors (>.4). All three methods of determining the number of factors to retain revealed a twofactor solution, accounting for 55.38\% of variance in initial Eigenvalues (Table 3). The items grouped on one factor appeared to embody global views on empathy in health care (7 items), while another factor was related to appraisal of personal empathy ability (4 items) as shown in Table 4. Cronbach's alpha for these factors were .84 (global views) and .77 (personal ability).

Analyses of administration data of the KCES indicated potential problems within the scale (above), and therefore thematic analysis was undertaken to investigate the response process of students when presented with the KCES. The thematic analysis from the cognitive interviews can be found in Table 5. The negatively-worded items were deemed confusing. Alternate scaling was discussed during the interviews, and consensus was achieved regarding the type of scale to use - necessity (the level of necessity for the attitude/behavior) vs. agreement (level of agreement with the attitude/behavior). Further, students indicated that there were significant differences in their own abilities versus the requirements of health care providers. When reading items, students often did not know which perspective to provide were they supposed to assume that they were the health care provider or health care providers in general?

Based on the psychometric data plus the cognitive interviews, the KCES was revised as follows: (1) key components of cognitive and affective empathy were retained, (2) scaling was changed to reflect necessity (the level of necessity for the attitude/behavior: unnecessary to extremely necessary) and ability to empathize (how well it describes me: does not describe me to describes me extremely well), (3) negatively-worded items were removed, and (4) instrument was changed to two parallel subscales. Thus, the KCES was revised (KCES-R) and contained two subscales: global health care professional empathy ratings and self-perceived empathy ratings. Students were directed that one section was related to health care professionals generally, while the other section was related to their personal ability. The two subscales are each comprised of seven items with parallel statements and a revised rating scale regarding necessity. The KCES-R was confirmed through 10 nursing student cognitive interviews which indicated no further changes were necessary.

\section{DISCUSSION}

This study used data from thousands of responses among geographically and professionally diverse samples. The data were utilized to examine the psychometric properties of the KCES and determine whether revisions were needed. In addition, cognitive interviews were utilized to provide meaningful information regarding challenges when completing the KCES. Through this process, modifications to the KCES were proposed to develop the KCES-R.

From this study, it appears that real world use of the original KCES is associated with certain problems that necessitate changes to the scale itself. Namely, or most glaring, the reverse-coded items from the KCES may be misinterpreted by respondents or interpreted in multiple ways, and users who calculate scores may not understand the procedure for reverse coding and scoring the items. This was first recognized through inspection of the item level statistics, but this finding was confirmed by student comments during cognitive interviews. Reverse-coded items have been found to be problematic in other research as well, with misinterpretation by respondents. ${ }^{20,21}$ Further, mixing positively- and negatively-worded items can impact validity and reliability; including these two types should be carefully done. $^{22,23}$

Possibly due to issues with the reverse coded items, but potentially also explained by other issues, this study did not find corroborating evidence of the dimensionality (cognitive and affective groupings) of the KCES. Instead, exploratory analyses and cognitive interviews unveiled two different factors. EFA found two factors that appeared to be centered on general expectations of empathy from health care providers and of their personal ability to empathize.

Individual perceptions of the importance of a skill or attitude will vary as well as an individual's personal ability to utilize the skill or demonstrate the attitude. Thus, it seems probable that these two factors are important. While similar to cognitive (understanding the patient's perspective) and affective (connecting to the patient's feelings) empathy, they represent the process of finding value in the skill and then working to attain it. ${ }^{8}$ However, attainment of a skill such as empathy often is not immediate and takes time to develop through experiences and interactions that can occur within the classroom and outside of the classroom. ${ }^{1}$ This seems to parallel ACPE accreditation standards supporting the development of empathy as a core component of the affective skills needed for practice and patient care. ${ }^{1}$ Thus, instruments need to 
assess both elements of expectations and personal skills in order to accurately determine student progression and efficacy of educational interventions.

Cognitive interviews again confirmed the assertions from the quantitative data -- students tended to find themselves thinking about others and general concepts for certain items and about themselves and their own ability for other items. However, it is important to note that, among the pharmacy students interviewed, it depended upon how close they were to practice (ie, it appeared that pharmacy students closer to graduation and practice viewed themselves as the health care professional more than did younger students). Students develop their professional identity (professional identity formation) as they interact with health care professionals and work through curricula. ${ }^{24}$ Thus, students closer to graduation may identify more with the profession, which may have been a reason why they more closely identified with health care professional during the cognitive interview process. This is another reason why cognitive interviews are useful to identify confusion related to items and assist with revising scale items. ${ }^{15}$ The scale was then revised to clarify the individual for whom the question related.

The amalgamation of the issues identified in psychometric analyses of the items and the scale, paired with findings from the first round of cognitive interviews resulted in several changes, which were then investigated in a second round of cognitive interviews. The second round of cognitive interviews confirmed the benefit of the revisions into two separate subscales related to global health care professional empathy ratings and self-perceived empathy ratings, revised scaling, and removal of negatively-worded items. This process provides a modified KCES-R scale with a strong development framework and evidence of validity. Further studies can provide additional validity evidence of the KCES-R.

\section{CONCLUSION}

Data from thousands of previous administrations of the KCES among geographically and professionally diverse samples were utilized to further investigate the psychometric properties of the KCES. Additionally, cognitive interviews were utilized to provide confirmation and clarification regarding challenges when completing the KCES. Based upon potential problems identified in quantitative analysis of the responses, student pharmacist cognitive interviews were conducted, modifications to the KCES were proposed, and nursing student confirmatory cognitive interviews were all utilized in creating the KCES-R. Further psychometric validation is needed regarding the KCES-R, but it could be useful in assessing student empathy development throughout the didactic and experiential curriculum.

\section{REFERENCES}

1. Ratka A. Empathy and the development of affective skills. Am J Pharm Educ. 2018;82(10):7192. doi:10.5688/ajpe7192

2. Miller WR, Rollnick S. Motivational interviewing: Helping people change. The Gilford Press; 2013.

3. Dambha-Miller H, Feldman AL, Kinmonth AL, Griffin SJ. Association between primary care practitioner empathy and risk of cardiovascular events and all-cause mortality among patients with type 2 diabetes: A population-based prospective cohort study. Ann Fam Med. 2019;17(4):311-318. doi:10.1370/afm.2421

4. American Association of Colleges of Nursing. The essentials of baccalaureate education for professional nursing practice. Accessed August 10, 2021, https://www.aacnnursing.org/portals/42/publications/baccessentials08.pdf

5. Accreditation Council for Pharmacy Education. Accreditation Standards and Key Elements for the Professional Program in Pharmacy Leading to the Doctor of Pharmacy Degree ("Standards 2016"). Published February 2015. https://www.acpe-accredit.org/pdf/Standards2016FINAL.pdf. Accessed August 10, 2021.

6. Accreditation Council for Pharmacy Education. Guidance for the Accreditation Standards and Key Elements for the Professional Program in Pharmacy Leading to the Doctor of Pharmacy Degree ("Guidance for Standards 2016"). Published February 2015. https://www.acpe-accredit.org/pdf/GuidanceforStandards2016FINAL.pdf. Accessed August 10, 2021.

7. Patel S, Pelletier-Bui A, Smith S, et al. Curricula for empathy and compassion training in medical education: A systematic review. PloS one. 2019;14(8):e0221412-e0221412. doi:10.1371/journal.pone.0221412

8. Kiersma ME, Chen A, Yehle KS, Plake KS. Validation of an empathy scale in pharmacy and nursing students. Am J Pharm Educ. 2013;77(5):94. doi: 10.5688/ajpe77594

9. DeVon HA, Block ME, Moyle-Wright P, et al. A psychometric toolbox for testing validity and reliability. $J$ Nurs Scholarsh. 2007;39(2):155-64. doi:10.1111/j.1547-5069.2007.00161.x

10. Haley B, Heo S, Wright P, Barone C, Rettigantid MR, Anders M. Effects of using an advancing care excellence for seniors simulation scenario on nursing student empathy: A randomized controlled trial. Clin Simul Nurs. 2017;13(10):511-519. doi:https://doi.org/10.1016/j.ecns.2017.06.003 
11. Harris KB, McCarty D, Wilson JA, et al. The use of a disease state simulation assignment increased students' empathy and comfort with diabetes nutrition counseling. Curr Pharm Teach Learn. 2018;10(9):1272-1279. doi: 10.1016/j.cptl.2018.06.017

12. Blaszczyk AT, Mahan RJ, McCarrell J, Sleeper RB. Using a polypharmacy simulation exercise to increase empathy in pharmacy students. Am J Pharm Educ. 2018;82(3):6238. doi:10.5688/ajpe6238

13. Hastings TJ, Kavookjian J, Ekong G. Associations among student conflict management style and attitudes toward empathy. Curr Pharm Teach Learn. 2019;11(1):25-32. doi: 10.1016/j.cptl.2018.09.019

14. Shires DA, Stroumsa D, Jaffee KD, Woodford MR. Primary care clinicians' willingness to care for transgender patients. Ann Fam Med. 2018;16(6):555-558. doi:10.1370/afm.2298

15. Peterson CH, Peterson NA, Powell KG. Cognitive interviewing for item development: Validity evidence based on content and response processes. Meas Eval Couns Dev. 2017;50(4):217-223. doi:10.1080/07481756.2017.1339564

16. Hu Lt, Bentler PM. Cutoff criteria for fit indexes in covariance structure analysis: Conventional criteria versus new alternatives. Struct Equ Modeling. 1999;6(1):1-55. doi:10.1080/10705519909540118

17. O'Connor BP. SPSS and SAS programs for determining the number of components using parallel analysis and velicer's MAP test. Behav Res Methods Instrum Comput. 2000;32(3):396-402. doi:10.3758/bf03200807

18. Streiner DL, Norman GR. Health measurement scales: A practical guide to their development and use. Oxford University Press; 2015.

19. Nunnally JC, Bernstein IH. Psychometric theory. 3rd ed ed. McGraw-Hill; 1994.

20. Hughes GD. The impact of incorrect responses to reverse-coded survey items. Res Sch. 2009;16(2):76-88.

21. Weems GH, Onwuegbuzie AJ, Lustig D. Profiles of respondents who respond inconsistently to positively- and negatively-worded items on rating scales. Eval Res Educ. 2003;17(1):45-60. doi:10.1080/14664200308668290

22. Chyung SY, Barkin JR, Shamsy JA. Evidence-based survey design: The use of negatively worded items in surveys. Perform Improv. 2018;57(3):16-25. doi:https://doi.org/10.1002/pfi.21749

23. Weems GH, Onwuegbuzie AJ. The impact of midpoint responses and reverse coding on survey data. Meas Eval Couns Dev. 2001;34(3):166-176. doi:10.1080/07481756.2002.12069033

24. Noble C, O’Brien M, Coombes I, Shaw PN, Nissen L, Clavarino A. Becoming a pharmacist: Students' perceptions of their curricular experience and professional identity formation. Curr Pharm Teach Learn. 2014;6(3):327-339. doi: 10.1016/j.cptl.2014.02.010 
Table 1. Kiersma-Chen Empathy Scale (KCES) Item and Scale Descriptive Statistics

\begin{tabular}{|c|c|c|c|c|c|c|c|c|}
\hline Items & Range & $\mathbf{n}$ & Mean & SD & Skewness & Kurtosis & IIC $^{\mathbf{a}}$ & ITC $^{\mathbf{b}}$ \\
\hline Cognitive Domain & $9-63$ & 7438 & 49.3 & 6.0 & -0.4 & 1.0 & & \\
\hline $\begin{array}{l}\text { 1.It is necessary for a HCP to be able to } \\
\text { comprehend someone else's experiences }\end{array}$ & $1-7$ & 7660 & 6.2 & 0.9 & -2.1 & 6.9 & $-.02-43$ & 0.39 \\
\hline $\begin{array}{l}\text { 3. I am able to comprehend someone else's } \\
\text { experiences }\end{array}$ & $1-7$ & 7417 & 5.7 & 1.0 & -1.1 & 2.2 & $-.01-.49$ & 0.38 \\
\hline $\begin{array}{l}\text { 4. I will not allow myself to be influenced by } \\
\text { someone's feelings when determining the best } \\
\text { treatment }^{c}\end{array}$ & $1-7$ & 7646 & 3.7 & 1.6 & 0.2 & -0.9 & $-.08-.58$ & 0.17 \\
\hline $\begin{array}{l}\text { 6. It is necessary for a HCP to be able to value } \\
\text { someone else's point of view }\end{array}$ & $1-7$ & 7279 & 6.4 & 0.8 & -2.3 & 8.8 & $.03-.46$ & 0.46 \\
\hline $\begin{array}{l}\text { 8. I am able to view the world from another } \\
\text { person's perspective }\end{array}$ & $1-7$ & 7422 & 5.6 & 1.1 & -1.2 & 2.7 & $-.03-.49$ & 0.46 \\
\hline $\begin{array}{l}\text { 10. I am able to value someone else's point of } \\
\text { view }\end{array}$ & $1-7$ & 7640 & 6.0 & 0.8 & -1.4 & 4.8 & $-.05-.43$ & 0.40 \\
\hline $\begin{array}{l}\text { 13. It is necessary for a HCP to be able to } \\
\text { identify with someone else's feelings }\end{array}$ & $1-7$ & 7266 & 6.0 & 1.0 & -1.4 & 3.1 & $.00-.63$ & 0.48 \\
\hline $\begin{array}{l}\text { 14. It is necessary for a HCP to be able to view } \\
\text { the world from another person's perspective }\end{array}$ & $1-7$ & 7428 & 6.0 & 0.9 & -1.2 & 2.3 & $-.02-.63$ & 0.52 \\
\hline $\begin{array}{l}\text { 15. A HCP should not be influenced by } \\
\text { someone's feelings when determining the best } \\
\text { treatment }^{\mathrm{c}}\end{array}$ & $1-7$ & 7430 & 4.0 & 1.7 & 0.0 & -1.0 & $-.01-.58$ & 0.24 \\
\hline Affective Domain & $10-42$ & 7439 & 34.3 & 4.5 & -0.4 & -0.2 & & \\
\hline $\begin{array}{l}\text { 2. I am able to express my understanding of } \\
\text { someone's feelings }\end{array}$ & $1-7$ & 7435 & 5.8 & 1.0 & -1.3 & 2.8 & $.03-.26$ & 0.24 \\
\hline $\begin{array}{l}\text { 5. It is necessary for a HCP to be able to express } \\
\text { an understanding of someone's feelings }\end{array}$ & $1-7$ & 6938 & 6.2 & 0.8 & -1.6 & 5.1 & $.02-.46$ & 0.26 \\
\hline $\begin{array}{l}\text { 7. I believe that caring is essential to building a } \\
\text { strong relationship with patients }\end{array}$ & $1-7$ & 7421 & 6.6 & 0.7 & -2.3 & 10.4 & $.10-.58$ & 0.36 \\
\hline $\begin{array}{l}\text { 9. Considering someone's feelings is not } \\
\text { necessary to provide patient-centered care }\end{array}$ & $1-7$ & 7631 & 5.1 & 2.0 & -0.9 & -0.5 & $.02-.62$ & 0.40 \\
\hline $\begin{array}{l}\text { 11. I have difficulty identifying with someone } \\
\text { else's feelings }{ }^{c}\end{array}$ & $1-7$ & 7421 & 4.7 & 1.7 & -0.6 & -0.8 & $.03-.62$ & 0.49 \\
\hline $\begin{array}{l}\text { 12. To build a strong relationship with patients, } \\
\text { it is essential for a HCP to be caring }\end{array}$ & $1-7$ & 7413 & 6.4 & 0.8 & -1.6 & 4.6 & $.09-.58$ & 0.32 \\
\hline Sum KCES & $27-78$ & 7439 & 83.6 & 8.4 & -0.6 & 1.4 & & \\
\hline
\end{tabular}

ainter-item correlations among items from either affective domain and cognitive domain; ${ }^{\mathrm{b}}$ corrected inter-item correlations among items from either affective domain and cognitive domain; ${ }^{\mathrm{c}}$ item reverse coded; SD standard deviation; HCP healthcare practitioner 
Table 2. Fit Indices for 1- and 2-Factory Confirmatory Models

\begin{tabular}{llll}
\hline & Evaluation Criteria & 2-Factor Model & 1-Factor Model \\
\hline Chi-square (df, $p)$ & & $13597.8(89,<0.01)$ & $13733.6(90,<0.01)$ \\
RMSEA (90\% CI) & $\leq 0.06$ & $0.14(0.14-0.14)$ & $0.14(0.14-0.14)$ \\
SRMR & $\leq 0.08$ & 0.10 & 0.10 \\
CFI & $>0.95$ & 0.64 & 0.64 \\
\hline
\end{tabular}

RMSEA root mean square error of approximation; SRMR standardized root mean square residual; CFI comparative fit index 
Table 3. Eigenvalues

\begin{tabular}{cccc}
\hline Factor & Eigenvalue & $\begin{array}{c}\text { Upper Threshold for Eigenvalue of Significance 95\% } \\
\text { Confidence Interval }\end{array}$ & $\begin{array}{c}\text { \% of } \\
\text { Variance }\end{array}$ \\
\hline 1 & 4.75 & 1.08 & 43.16 \\
2 & 1.34 & 1.06 & 12.22 \\
3 & 0.81 & 1.04 & \\
4 & 0.77 & 1.03 & \\
5 & 0.67 & 1.02 & \\
6 & 0.61 & 1.01 & \\
7 & 0.55 & 1.00 & \\
8 & 0.45 & 0.99 & \\
9 & 0.38 & 0.98 & \\
10 & 0.36 & 0.96 & \\
11 & 0.32 & 0.95 & \\
\hline
\end{tabular}


Table 4. Factor Loadings from EFA of 11 KCES Items

\begin{tabular}{lcc} 
& Factor 1 & Factor 2 \\
\hline 1. It is necessary to comprehend someone else's experiences & .46 & .68 \\
2. I am able to express understanding of someone's feelings & & .73 \\
3. I am able to comprehend someone else's experiences & & \\
5. It is necessary to express understanding of someone's feelings & .60 & .59 \\
6. It is necessary for healthcare practitioner to express understanding of someone's & \\
feelings & .66 & \\
7. Caring is essential to build strong relationships with patients & \\
8. I am able to view the world from another person's perspective & .64 \\
10. I am able to value someone else's point of view & .76 \\
12. It is essential for healthcare practitioner to be caring to build strong & \\
relationships & .66 \\
13. It is necessary for healthcare professional to identify with someone else's \\
feelings \\
14. It is necessary for healthcare practitioner to view world from another person's \\
perspective
\end{tabular}


Table 5. Thematic Analysis of the Cognitive Interviews

\begin{tabular}{|c|c|c|}
\hline Category & Theme (n Participants) & Exemplar Quote \\
\hline \multirow[t]{3}{*}{ Judgment/Estimation } & Positive overall impression (7) & $\begin{array}{l}\text { "I liked it. I think especially in health care I } \\
\text { think this is for me one of the most important } \\
\text { things." }\end{array}$ \\
\hline & $\begin{array}{l}\text { Comfortable answering all } \\
\text { questions (6) }\end{array}$ & "I felt very comfortable." \\
\hline & All items necessary to do (4) & $\begin{array}{l}\text { "I can't imagine anyone saying no to them } \\
\text { because I said extremely necessary for almost } \\
\text { all of them." }\end{array}$ \\
\hline \multirow[t]{2}{*}{$\begin{array}{l}\text { Social } \\
\text { Context/Meaningful } \\
\text { Capture of Life of } \\
\text { Patient }\end{array}$} & $\begin{array}{l}\text { Empathy: seeing the perspectives of } \\
\text { others (6) }\end{array}$ & $\begin{array}{l}\text { "I think empathy is just kind of like being able } \\
\text { to like level with people and being able to see } \\
\text { like through their eyes and be able to help } \\
\text { them." }\end{array}$ \\
\hline & $\begin{array}{l}\text { Empathy is understanding patients } \\
\text { (4) } \\
\text { Culture and beliefs could be } \\
\text { integrated ( } 3 \text { ) }\end{array}$ & $\begin{array}{l}\text { "I think empathy to me is like being able to } \\
\text { understand ... the feelings of someone else." } \\
\text { "An extra question regarding culture would be } \\
\text { nice." }\end{array}$ \\
\hline \multirow{3}{*}{$\begin{array}{l}\text { Selection of Response } \\
\text { to Question/ } \\
\text { Comprehension }\end{array}$} & $\begin{array}{l}\text { Unsure of who they should respond } \\
\text { as - self or others (4) }\end{array}$ & $\begin{array}{l}\text { "What am I identifying - like their feelings in } \\
\text { general or am I taking on their feelings?" }\end{array}$ \\
\hline & Some items too similar (3) & $\begin{array}{l}\text { "I think that some of them were a little bit too } \\
\text { similar. Just like the comprehend experience } \\
\text { and identify with feelings." }\end{array}$ \\
\hline & Some aspects too non-specific (2) & $\begin{array}{l}\text { "I feel like the insert group here thing is } \\
\text { confusing." }\end{array}$ \\
\hline
\end{tabular}

